https://helda.helsinki.fi

\title{
What's the future for heritage crime research?
}

\section{Grove, Louise}

Palgrave Macmillan

2014-10

Grove, L \& Thomas, S 2014 , What's the future for heritage crime research? in L Grove \& S Thomas (eds) , Heritage Crime : Progress, Prospects and Prevention . Palgrave Macmillan, Basingstoke, pp. 224-230 .

http://hdl.handle.net/10138/303001

acceptedVersion

Downloaded from Helda, University of Helsinki institutional repository.

This is an electronic reprint of the original article.

This reprint may differ from the original in pagination and typographic detail.

Please cite the original version. 


\section{Chapter 13: What's the Future for HeritageCrime Research?}

Louise Grove and Suzie Thomas

In Grove, Louise, and Suzie Thomas (eds). Heritage crime: progress, prospects and prevention. Springer, 2014. pp. 224-230.

This volume has drawn together contributions on heritage crime from around the globe. Authors have drawn attention to the plight of heritage in their respective countries and shone a light both on laudable practice and areas that need further attention. Time and again authors have called for more understanding of the issues at both micro and macro levels. Cooperation and collaboration are seen as key to the success of future endeavours to protect the world's heritage.

In this final chapter we pull together these arguments and cast a critical eye over the gaps in our knowledge. In developing a greater understanding of what is meant by heritage crime, the book has drawn on examples from around the world, including rock art, forestry, protected buildings, religious assets and archaeological sites. The different crime problems which face these sites are varied, including theft and looting, criminal damage and graffiti, as well as broader issues related to the failure to protect against unnecessary development at sites. We break these issues down by the themes of the book - first, applauding the progress that has been made in different jurisdictions; second, considering the prospects for heritage crime by examining the steps that are already being taken to tackle the problem, with an eye to the future; and third, discussing whether prevention of heritage crime in various contexts might be possible.

We need to draw on existing expertise from across the disciplines, working with practitioners and volunteers both to understand the issues around heritage crime and to develop and deliver a programme to tackle the problem at local, national and international levels. We also call for further research to increase our understanding of heritage crime around the world and develop effective responses to the different problems it poses.

\section{Progress}

There is much to be positive about in the world of heritage crime. While there is inevitably a long line of failures, such as the countless sites and monuments already devastated by the work of treasure seekers and other looters, the contributors to this volume have also identified examples of where success has been evident, where prosecutions have been brought and where educational programmes have been implemented. Progress, therefore, is evident in the field and superb examples of best practice can be shared both within and across jurisdictions.

There is a growing recognition of the ways in which heritage professionals can learn from other experts whether these are from different disciplines or from different countries. Wennberg discussed the possibility of Norway learning from the UK's Portable Antiquities Scheme, despite acknowledged flaws in this programme (see for example Gill, 2010). The chapter by Price, Sidebottom and Tilley is one example of how police and academics are starting to work together to examine the heritage crime problem in the UK. Indeed, this entire volume illustrates the potential for collaboration across disciplines, work environments and jurisdictions.

There is also an understanding being developed around the notion of different motivations behind offences. Wilful neglect, malicious intent and lack of awareness may all lead to similar outcomes in terms of the damage to heritage, but can and should be treated very differently in terms of future prevention and 
indeed in the courts. As with many crimes, financial motivation is a significant driver within the heritage environment and we are starting to recognize some patterns to this effect. Price, Sidebottom and Tilley linked the price of metal with the theft of lead from church roofs, for example, while Benson and Fouché noted that thefts of objects from museums reflect a certain awareness of market demands.

Legislation, treaties and guidance have all been developed in recent years. Shelbourn applauded the use of sentencing guidance in the USA, suggesting an increase in sentencing where cultural items are involved in an offence; and introduced the recent innovation of Heritage Crime Impact Statements, which in England and Wales allow for a greater explanation to the courts about the effect of offences on cultural heritage. While these cannot be seen as entirely successful in all instances, they certainly represent a step in the right direction for the prosecution of heritage offences. Cross-border working is also in evidence, with Musteat, ac identifying a number of cases where cooperation.

\section{Prospects}

Designation of sites as being entitled to protection is perhaps the first step to ensuring the longevity of heritage assets. Identification of the most relevant, or even 'deserving' sites is not always accurate and despite efforts to ensure that local groups have some say over the status of certain assets (for example the Localism Bill in the UK), in many locations assets are not afforded the protection they deserve. As Laulumaa pointed out, the process of acknowledging an asset as worthy of wider protection becomes meaningless if enforcement is sporadic and patchy. If developers and others can, in effect, buy their way out of the sanctions placed on them for damaging heritage, the regulations also become meaningless. Throughout this book, we have seen a recurring theme of power and powerlessness. Too often, it seems, the power to protect an asset is taken out of the hands of those who have a true stake in making success out of its management or a real interest in its meaning as a place of significance. Private companies are identified as causing a distinct issue for the protection of heritage by both Wennberg and Tantaleán. A question is raised time and again about the complicity of authorities in the issues of exploitation of cultural heritage whether this is wilful or neglectful; stemming from ignorance or a different set of priorities; historical or current. Hardy argued that it may be an artefact of the present situation that the destruction of Cyprus's heritage is in part a side effect of other conflict. We have seen this elsewhere in recent years, with Syria, Egypt and Iraq, among others, all suffering loss and destruction of heritage in the wake of war and uprisings. The concept that too many agencies turn a blind eye to and fail to ask questions about, the provenance and provenience of cultural objects, is one raised by Polk. Even where questions are asked, proof of ownership is problematic, particularly, as Vollgraaff argued, when items are out of their nation state.

Tantaleán also raised the issue of the legacy left by previous generations. Many private collections predate the illegality of (for example) looting from archaeological sites. Indeed, it can be argued that many museum collections around the globe are based on a system which, were it to be continued today, would be seen as illicit activity in most jurisdictions. As such, Wennberg's suggestion of an amnesty on existing collections of archaeological finds has a certain logic: it would enable the heritage to be documented and examined, without owners fearing prosecution over possession. Such a move would without doubt be controversial however and, moreover, would risk exacerbating a pre-existing problem.

A recurring theme throughout the chapters herein is that of opportunity. It is perhaps self-evident that for offences to be committed an opportunity needs to exist. Yet too often we pay little attention to where those opportunities lie. Vollgraaff alluded to this, where the assistance of a museum employee was considered to be a likely element in the commission of a theft. Polk detailed the existing points where opportunities exist and at which interventions within the illicit trafficking of cultural objects may be possible. Mapping out and understanding the shape of the international chain is arguably the first step in 
identifying where this acquisition and distribution network may be interrupted. The market and opportunities should also be understood more broadly. Benson and Fouché made the point that there is an 'ideal' type of heritage object to trade - one that is not too rare, as these are riskier to find a buyer for, but that is still limited enough to be of value. Understanding these core issues of target, location and offender (as outlined by Grove and Pease) may enable preventive strategies to be developed.

\section{Prevention}

It may seem glib to suggest that education is a key tool in the protection of heritage assets for the future, yet this is a theme which emerges repeatedly from contributors to this volume. Grove and Pease identified the work being done by charities in the heritage sector to raise awareness of crime against heritage assets and suggest that this needs to be ramped up. Certainly, work with such groups facilitates the delivery and development of education materials, but this is acknowledged to be far from practical in all contexts. It is perhaps particularly salient where damage is caused not by wilful intent, but rather an ignorance of the effect of behaviour, such as the rock art destruction outlined by Vollgraaff. Wennberg called for an increased awareness of the damage to heritage on a local, national and international level. Delivering such a broad scale programme would involve the cross-border cooperation of governments, charities and other institutions. Education is essential on a multitude of levels. Vollgraaff noted the lack of experience of officials in some areas - training of professionals is essential to maintain the integrity of the sites they are charged with protecting. Sharing information and examples of good practice both within and across borders would progress this process exponentially. We can, and perhaps should, take this opportunity to learn from other nations. Tantaleán praised the existing provision within Peruvian schools which makes history a compulsory part of the curriculum and includes discussions of archaeological heritage. However, there is far less awareness within the general populace and, as with all education programmes, it will take a long time for the knowledge to become integrated into the mainstream consciousness. Education, therefore, is but one strand of prevention, and a long term strategy rather than an immediate opportunity.

We turn now to other routes to preventing criminal behaviour causing damage to heritage assets. Price, Sidebottom and Tilley showed that there is a potential link between specific features of churches and the risk of lead being taken from them. This suggests that we should be able to predict which sites are at greater risk and develop preventive approaches for these assets accordingly - an approach which is detailed in more depth by Grove and Pease. Here, once more we see the importance of drawing on interdisciplinary approaches to tackle the risk to our heritage.

\section{Next steps in research}

This volume has presented a global snapshot of our present knowledge and understanding surrounding heritage crime issues. We have seen how the scarcity of resources and knowledge has had an adverse impact on the development of effective strategies to date. We have seen, too, evidence of the high quality work that is already being conducted by dedicated practitioners and researchers around the world. In most regions, there are people who at least understand the problem, even if no successful solutions have yet been found or implemented. Yet there is much we still do not know. Here, we outline what we see as the next logical steps in tackling heritage crime.

First, we need to improve upon the existing knowledge base. Presently, much of the information we have about heritage crime exists in silos in different countries and organizations. Regular surveys, akin to the International Crime Victimization Survey, would be of great benefit to researchers and practitioners alike. This would allow patterns and trends to emerge and feed into informing strategies around the improvement of the prevention and detection of heritage crime in the future. There are specific hurdles to be overcome with such an ambitious project, including (but not limited to) the problems of unstaffed and or remote sites, identification of relevant assets and points of contact, and language standardization. 
Specifically, there needs to be common terminology developed, to avoid issues which currently affect the measurement of heritage crime, such as the conflation of looting with the many broader problems faced by heritage sites around the world. Collection of data would benefit from being regular, systematic and international in scope.

We recognize that this is ambitious in nature and suggest that, as an interim measure, guidelines could be offered to policing institutions and heritage organizations to allow the separate recording of heritagerelated offences. Existing data, such as that from police records, could be mapped onto known heritage sites, or a central database could be established to allow individuals and organizations to record their victimization to allow researchers and practitioners to examine the cases in detail and encourage information sharing. More innovative approaches are also worthy of consideration, such as the use of crowdsourcing to identify at risk sites (for example by encouraging people to examine photographs of sites for changes which may be indicative of criminal damage). Polk began the arduous process of identifying pinch points at which prevention can be introduced - improving our data and knowledge bases will facilitate the detail to be drawn out of this. The importance of improving the knowledge base cannot be overstated. It is the first step to enabling the most 'at risk' sites to be identified and enables the prioritization of resources accordingly.

There are both macro and micro approaches which may be useful once these priorities are ascertained. A range of partners might have responsibility for implementing these, ranging from individuals and single organizations, to government and cross border organizations - or a combination of these. In the first instance, existing legislation should be used to its full effect wherever possible. Wennberg and Laulumaa in this volume each identified this as a particular failure and Shelbourn has made some suggestions for government level interventions where current legislation is insufficient. Ensuring prosecution under existing legislation could act as a deterrent, particularly where penalties are punitive enough to draw media attention. Hardy noted that there are possible links between heritage and organized crime. This links directly to the criminological concept of self-selection policing as developed by Roach (2007) which outlines how individuals involved in relatively small scale offences may also be guilty of much more serious crimes.

This is a hypothesis worthy of testing within the field of heritage crime, as should these links be evidenced, it may provide impetus for the injection of further funding into the detection and prevention of offences against cultural heritage.

The development of further educational policies around the significance of heritage assets may be a long term strategy, as noted above, but one worthy of consideration by heritage organizations and governments alike. With the growing movement of community heritage stewardship in some countries, monitoring for criminal damage could be added relatively easily into the activities of voluntary groups charged with caring for heritage sites. Where heritage organizations are already involved with delivering educational activities, sharing best practice about broadening their reach to under-represented groups would be a logical next step. Indeed, sharing best practice is something to be encouraged both within and across borders. The establishment of a database within heritage protection would allow the wealth of practitioner expertise to be drawn on, while acknowledging grassroots priorities and experiences.

Case studies, broader research and data could be shared on a common site which allows open access to material. Theoretically, if money truly were no object, the website could be complemented by other opportunities for dissemination and communication of successes and failures, such as international meetings or simply webinars that could be accessed internationally. The benefits of tourism to many heritage assets may be great, but sharing experiences in such a way may allow for an easier examination of maximizing the positives and minimizing the negatives of increasing footfall to public sites. 
We propose that many of the above suggestions would best be facilitated via an interdisciplinary network made up of academics and practitioners from around the globe. This would allow theories and concepts from archaeology, heritage management, law, criminology and others to be drawn together and tailored to specific contexts in different countries, settings and sites. We have been fortunate to work with many passionate people in the creation of this book and have been made aware of many more working in the field. We are confident that tapping into this resource would enable impressive developments to be made in the prevention and detection of heritage crime, ensuring the protection of our cultural heritage for future generations.

\section{References}

Gill, D. (2010) 'The Portable Antiquities Scheme and the Treasure Act: Protecting the Archaeology of England and Wales?', Papers from the Institute of Archaeology, 20, 1-11. Doi: available at: http://dx.doi.org/10.5334/pia.333.

Roach, J. (2007) 'Those Who do Big Bad Things Also Usually Do Little Bad Things: Identifying Active Serious Offenders Using Offender Self-Selection', International Journal of Police Science and Management, 9(1), 66-79. 